\title{
Erratum to: Morphological and physiological acclimation of Catalpa bungei plantlets to different light conditions
}

\author{
J.W. WU, ,\# , Y. SU*, , J.H.WANG ${ }^{* *,+}$, Q. HE*, Q. QIU*, J.W. MA***, and J.Y. LI",+
}

Guangdong Key Laboratory for Innovative Development and Utilization of Forest Plant Germplasm, College of Forestry and Landscape Architecture, South China Agricultural University, 510642 Guangzhou, China*

State Key Laboratory of Tree Genetics and Breeding, Key Laboratory of Tree Breeding and Cultivation of State Forestry Administration, Research Institute of Forestry, Chinese Academy of Forestry, 100091 Beijing, China ${ }^{* *}$

Xiaolongshan Forestry Science and Technology Research Institute, 741022 Tianshui, China***

Erratum to: Photosynthetica

DOI: $10.1007 / \mathbf{s} 11099-017-0706-3$

The legend was added in Fig. $4 A$.

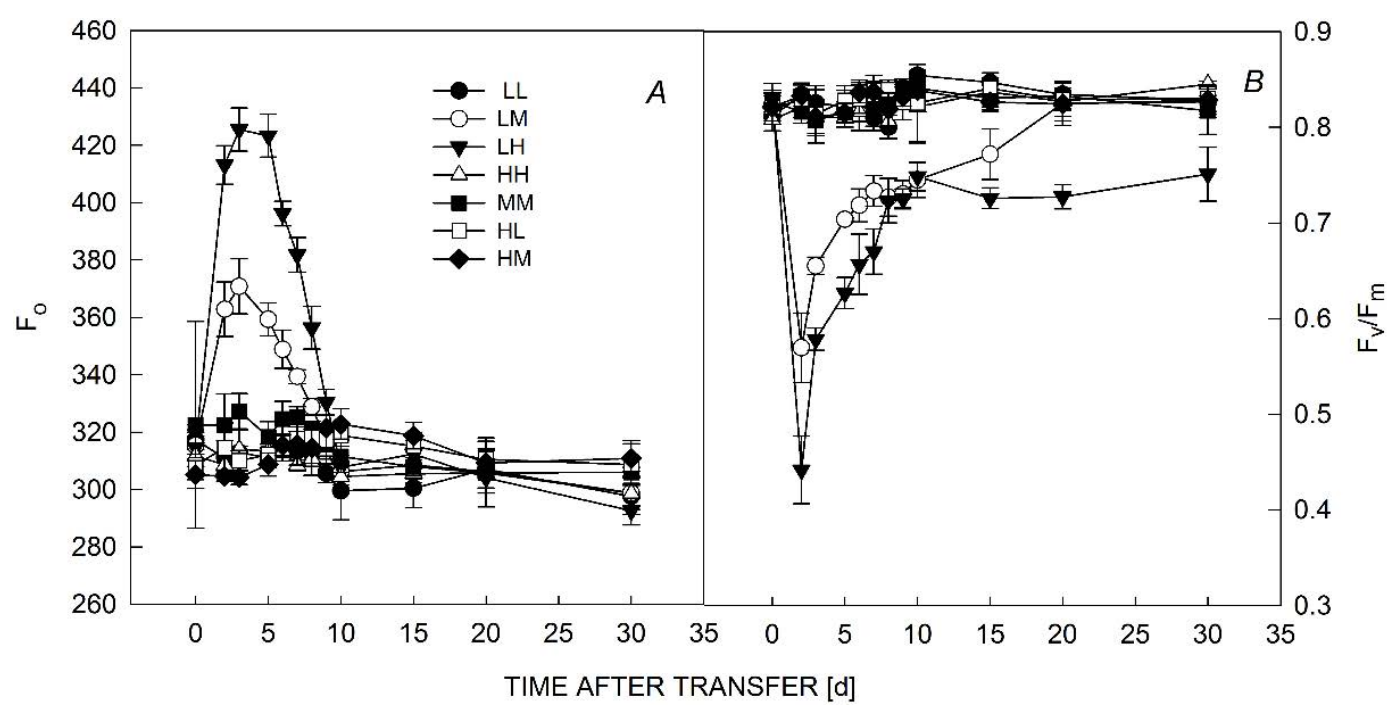

Fig. 4. Time course of the initial fluorescence of PSII $\left(\mathrm{F}_{\mathrm{o}}\right)(A)$ and variable fluorescence $\left(\mathrm{F}_{\mathrm{v}} / \mathrm{F}_{\mathrm{m}}\right)(B)$ in existing-old leaves of Catalpa bungei seedlings after transfer. Error bars show $\pm \mathrm{SD}$.

The publisher and authors apologize for these errors and for inconveniences they may have caused.

The online version of the original article can be found under doi: 10.1007/s11099-017-0706-3

${ }^{+}$Corresponding authors; phone: +86-20-85280962, fax: +86-20-85280256, e-mail: liyue@,scau.edu.cn, wangjh808@sina.com 